\title{
A LUANDA DE LUANDINO
}

\author{
THE LUANDINO'S LUANDA
}

Tania Macêdo*

Agora sou o griot, contador de histórias que não começam

e não terminam nunca.

Paula Tavares, A cabeça de Salomé, p. 43

E mostrava o mapa: complicações que sempre a vida nunca tem, cifra de Bíblia, locais versículos. [...] Mas o lugar era falseado, lá se dava o encontro só outro mapa, igual ao do primeiro. Luandino Vieira, No antigamente, na vida, p. 19

\section{RESUMO}

O texto apresenta algumas das coordenadas do trabalho artístico de José Luandino Vieira em Luuanda, procurando demonstrar como esse livro constrói sua autonomia literária frente ao real, quer no que concerne à linguagem, à geografia ou às personagens, sem que no entanto destrua os seus vínculos com a História.

PALAVRAS-CHAVE: José Luandino Vieira; Luuanda; Luanda e Literatura.

\section{ABSTRACT}

The text presents some of the features of José Luandino Vieira's artwork in Luuanda, trying to demonstrate how this book builds its literary autonomy, either in relation to language, geography or characters, without however destroying its ties with History.

KEYWORDS: José Luandino Vieira, Luuanda; Luanda and Literature. 
Escrito na prisão de São Paulo, na capital de Angola, em meio a numerosas dúvidas, desânimos e esperanças ${ }^{2}$, o livro Luuanda, composto de três contos, tem, como sabemos, uma história atribulada, já que foi "contrabandeado" para fora da cela pela esposa do autor, que o inscreveu no Prêmio de Novelística. A obra ganharia o concurso, mas uma campanha difamatória na mídia da época, a prisão de parte do júri que outorgara o prêmio e a dissolução da sociedade que o instituíra não permitiu que o autor fosse efetivamente agraciado.

Passados cinquenta anos desses acontecimentos, algumas publicações ajudam a iluminar melhor os mesmos, assim como o livro de Luandino. No primeiro caso, merece destaque a recolha organizada por Francisco Topa ${ }^{3}$ que estampa as críticas realizadas no momento da publicação da primeira edição de Luuanda, os documentos policiais, os pareceres da Sociedade de Novelística, assim como a reprodução dos textos jornalísticos da época que mostram a violência da campanha levada a efeito contra José Luandino Vieira e seu livro. Como se pode inferir, trata-se um volume incontornável para conhecer a história ao redor das três estórias escritas na capital de Angola.

O outro título, que nos fornece dados interessantes para compreendermos melhor a própria escrita literária de Luandino, consiste em um alentado volume com mais de mil páginas e que congrega os cadernos do cárcere do escritor. O subtítulo do livro, "Apontamentos, diário, correspondência (1962-1971)", explicita o heterogêneo material e o extenso arco temporal que o compõem, e que permitem ao leitor não apenas penetrar nas celas do regime colonial português, como também nos possibilita acompanhar a gênese de alguns dos personagens e estórias do autor. Veja-se, por exemplo, como os traços de um pequeno meliante trancafiado na mesma prisão de Luandino comporão, futuramente, uma das personagens de "Estória do ladrão e do papagaio". O jovem malandro é descrito em Luuanda como "Um rapaz coxo, estreitinho, puxa sempre a perna aleijada. Mulato. [...] um mulato-claro, o nome dele é Garrido, olhos azuis, quase um monandengue ainda, não é?" (VIEIRA, 1982, p. 38) ${ }^{4}$. Entre outras características, sempre positivas, desse monandengue do musseque, há um traço de seu falar que merece ser referido:

Na boca estreita de Garrido Fernandes tudo é por acaso. E as pessoas que lhe ouvem falar sentem mesmo o rapaz não acredita em sim, não acredita em não. Uma vez falou tudo o que ele queria não saía mais certo e tudo o que ele não queria também o caso era o mesmo; só passava-se tudo por acaso. Então, por acaso, vamos lhe encontrar na hora das cinco e tal no dia de ontem. Então, por acaso, vamos lhe encontrar na hora das cinco e tal no dia de ontem desse dia em que agarraram o Lomelino carregando o saco com os patos proibidos, metido na sombra da mandioqueira do quintal da Viúva, esperando Inácia. (VIEIRA, 1982, p. 38) 
Sem afirmar nada, para o Garrido de "Estória do ladrão e do papagaio" tudo é "por acaso"; ainda que no momento em que enfrenta seus comparsas Lomelino e Via Rápida torne-se assertivo, seu caráter é desenhado a partir da oscilação. Esse adolescente cujos traços são dados com grande positividade pelo narrador - a ponto de o mesmo assumir a expressão "por acaso" da personagem para iniciar a narração dos acontecimentos do dia em que os "causos" ocorreram - tem uma gênese descrita em Papéis da prisão:

\section{1-7-63}

Chama-se Antonio Fernandes Garrido. Pergunta-me sempre se tenho "Jornal d'hoje". Ontem perguntei-lhe porque? Por acaso é para ver se vem o nome dos detidos.

Disse-lhe que só a "província”. Agora não me larga. A razão: quer ver o nome dele no jornal! É baixo, magro e nodoso, com uma pequena cabeça de pássaro esperto. Camurcina azul, da marinha. Calções e quedes. Coxo duma perna, recordação de paralisia infantil. Está preso porque matou um papagaio! O bicho era bonito e falava bem e ele não gramava a dona! Pergunto-lhe, olhando para a pele bem clara dele e o restante aspecto:

- É cap'verde?

- Por acaso sou mestiço!

- De Luanda!

- Por acaso de fora de Luanda!

"Tudo por acaso..."

E não me larga mais para ler o jornal onde pensa virá o nome e a história do papagaio (Louro) que é o seu orgulho. (VIEIRA, 2015, p. 351)

A curiosidade inicial do escritor, que o faz inclusive realizar um desenho de Antonio Garrido em seu diário, seguida de uma certa irritação pelo fato de o mesmo não o "largar mais", será substituída no conto por uma grande simpatia pelo jovem habitante do musseque que rouba o papagaio da amada, a jovem Inácia. É interessante flagrar a passagem do real extratextual da cadeia à "estória" da esquadra, na medida em que o trabalho artístico de Luandino Vieira se configura a partir da solidariedade com as personagens marginalizadas, com uma linguagem em que não se sobrepõe a voz do narrador à das criaturas do relato, e que deixa entrever uma função da literatura.

Com esse exemplo, cremos que é possível refletir sobre a transfiguração artística operada pelo autor a partir da cidade de Luanda e seus habitantes, o que propicia afirmar que, passados cinquenta anos de sua publicação, o livro de José Luandino Vieira ainda mobiliza as emoções dos leitores e instiga a crítica, demonstrando a atualidade "de uma obra que se mantém em circulação e que suscita novas leituras", como aponta Francisco Topa $(2014$, p. 5).

E Luuanda ainda diz muito: por exemplo, na geografia amorosa que se descortina ao leitor das três estórias do livro, pois os becos e ruas, ave- 
nidas e vielas de Luanda são recriados e palmilhados pelas personagens de Luandino Vieira e com eles é possível conhecer as ruas da Baixa, seja a dos Mercadores, das Flores, os becos ou então os musseques: Braga, Makulus$\mathrm{su}$, Lixeira e as suas tortas ruas. Essa Luanda que emerge das estórias, como veremos, parece confundir-se com a cidade de pedra ${ }^{5}$, a Luanda extratextual. Um olhar atento, contudo, permite desmentir a identificação, pois a construção estética ultrapassa a geografia e foge ao documento sociológico. Mas, dialeticamente, se ancora e demonstra um conhecimento de Angola: sua música, sua culinária, sua história e suas utopias, confundindo-se com o desejo dos angolanos por liberdade. Dessa forma, pode-se afirmar que a Luanda dos textos de Luandino Vieira é realidade literária complexa que reflete e refrata Angola, mas de forma que uma enorme gama de singularidades locais, de fauna, flora e geografia, receba um tratamento artístico em que se dissolvem as fronteiras regionais - e Luanda se torna o mundo.

Frente à açambarcante presença da cidade nos textos, não raro assalta-nos a tentação de decodificar a cidade escrita a partir da geografia, como se a ficção fosse uma espécie de fac-símile dos mapas e, portanto, passível de ser situada em latitudes e longitudes. Um engano, pois a Luanda dos textos está distante da "cidade de pedra" e erige-se pelo poderoso verbo do autor.

E aqui talvez estejamos frente a alguns dos vários enigmas propostos pela escrita do autor de Nós, os do Makulussu: como se entrelaça a Luanda reinventada pela literatura com a cidade de pedra? Quais as funções que ela exerce nos textos, já que a Luanda de Luandino Vieira é realidade literária complexa que remete não apenas à cidade, mas também a Angola e ao mundo?

Para tentar avançar algumas respostas, dada a complexidade com que se tece o espaço nos textos luandinos, buscaremos pistas nas sendas abertas pelo crítico brasileiro Antonio Candido, que, no ensaio "O direito à literatura", reflete sobre o papel humanizador da escrita e sobre algumas de suas funções. Diz ele:

Analisando a literatura, podemos distinguir-lhe pelo menos três faces: 1) ela é uma construção de objetos autônomos como estrutura e significado; 2) ela é uma forma de expressão, isto é, manifesta emoções e a visão do mundo dos indivíduos e dos grupos; 3 ) ela é uma forma de conhecimento, inclusive como incorporação difusa e inconsciente" (CANDIDO, 2004, p. 176)

Segundo o crítico, inferimos que os textos literários atuam em nós em função dos conteúdos veiculados, já que essa é a parte mais visível dos mesmos. Todavia, ele alerta que o "impacto de uma produção literária, oral ou escrita, é devido à fusão inextricável da mensagem com a sua organização". E prossegue:

Quando digo que um texto me impressiona, quero dizer que ele impressiona porque a sua possibilidade de impressionar foi determinada pela ordenação recebida de quem o produziu. (CANDIDO, 2004, p. 178) 
No tocante aos textos de Luandino Vieira, a linguagem em que eles se expressam remete a uma organização do mundo em que a língua portuguesa é trabalhada de forma que sua estrutura sofra fraturas e acomodações, em face do substrato do quimbundo, em um movimento de astúcia à qual nos referiremos mais detidamente à frente. Equivalendo à força telúrica de um vulcão que irrompe com o magma da língua africana, um novo solo se estabelece. Muitos já fizeram referência à singularidade linguística dos textos de Luandino, descrevendo-a e mapeando-a. O que nos interessa é destacar o seu papel na construção da Luanda da escrita, já que a "fala" da cidade da literatura a que nos viemos referindo foge das regras do português padrão para se estabelecer no terreno de línguas em trânsito.

Assim, a escrita de Luandino Vieira, apesar da vinculação ao falar dos musseques luandenses, vai além. Tal como ocorre com a geografia de suas estórias, a "língua luandina" escapa ao documental, movimentando uma dinâmica em que o poético (ou seja, as necessidades de composição) estabelece as ousadias no território da linguagem. Dessa maneira, se o quimbundo pode ser visto como a origem de grande parte das inovações ali encontradas, não podemos ter a ilusão de que haja falantes que se expressem da mesma maneira que as personagens das estórias. Ao criar neologismos e subverter a estrutura do português, a escrita do autor detém o mérito dos grandes empreendimentos da literatura de nosso tempo: obriga a avançar devagar, não apenas pelas inovações linguísticas apresentadas a cada passo, como também pela perplexidade frente à nova postura de fruição dos textos que acaba por se impor. A ficção de Luandino Vieira, então, força o leitor a rever seus conceitos de literatura, arte e linguagem, em um esforço de dupla orientação: tomar distância dessa ficção, vinculando-a a valores universais, ao mesmo tempo em que busca sua localização em uma geografia literária. Assim, sem se aperceber, o descodificador das "estórias" do autor angolano vai sendo mobilizado a repensar seus códigos estéticos, suas estruturas linguísticas, em um esforço de entendimento do universo narrativo apresentado. A prosa de Luandino Vieira, portanto, ao partir de referências situacionais, acaba por inscrever-se na vertente da modernidade, ao apresentar o questionamento da linguagem do quotidiano e solicitar a participação efetiva do leitor.

Segundo entendemos, não se trata de uma opção estilística ancorada apenas no lúdico que a linguagem pode propiciar, na medida em que sua escrita inscreve-se como proposta emancipadora quando traz as estruturas do quimbundo, língua africana, como elemento desestabilizador do português. Ou seja, trata-se de experimentar as potencialidades do português, reinventando-o ao ultrapassar normas e apontando-lhe uma nova geografia e pertença: a angolana. O que implica uma utopia que ultrapassa a estética, já que indigita um projeto também educacional e político: reinventar o português de Angola, propondo a base de uma nova nação.

Sendo ao mesmo tempo um objeto em que se inscrevem a ética e a estética, a linguagem em Luuanda remete ao mundo do musseque, 
da oralidade e da oratura, na medida em que o quimbundo falado pelos moradores dos bairros suburbanos referidos nos textos (o Sambizanga, o Lixeira) atravessa as falas das personagens e dos narradores, situando-os não apenas geograficamente, mas também em termos linguísticos. Mas há também as marcas da oralidade nas repetições de vocábulos, na constante parataxe ou ainda nos desvios de linguagem próprios da língua falada. Notável ainda o quadro da oratura em que se inscrevem as estórias, na medida em que os missossos "enformam" os relatos, como se pode verificar no início e término das mesmas, que remetem ao introito e final dos contos tradicionais.

Refira-se que, além do conhecimento latente que a forma linguística do texto de Luandino apresenta a partir de sua linguagem, há um conhecimento, digamos, intencional, ou seja, planejado pelo autor e conscientemente assimilado pelo leitor. Veja-se, por exemplo, a questão da música, referida várias vezes em Luuanda a partir do conjunto musical N'Gola Ritmos, ou ainda a culinária ("panela de feijão d’azeitepalma, farinha, peixe frito, banana, pão. Comida de gente de musseque"), que é capaz de reconciliar amizades - como a de DosReis e Garrido de "A estória do ladrão e do papagaio". Dessa forma, com a música ou partilhando a cor e o cheiro bom do óleo de palma, Luuanda franqueia ao leitor um conhecimento de Angola: sua música, sua culinária, suas histórias e suas crenças.

Na mesma senda, temos as personagens, constituídas sobretudo das gentes do musseque, espécie de metonímia dos angolanos e que constituem uma vasta galeria de tipos: de verdadeiros malandros como Lomelino dos Reis e seus companheiros Via Rápida e Kam'tuta, do conto "Estória do ladrão e do papagaio" (Luuanda, 1972), mulatas assanhadas como Inácia, da mesma estória, o contínuo Xico João ("magro e não muito alto, usava mesmo aquele passo elástico característico dos queridos das moças da farras, dos miúdos das claques de futebol"), do romance $A$ vida verdadeira de Domingos Xavier (1974), o pedreiro diambeiro (ou seja, maconheiro) Sobral (Velhas estórias, 1974), até mulheres nada pacíficas como Nga Zefa, por exemplo, que se apresenta ao leitor com uma fala em que Nga Bina é chamada de "ladrona, feiticeira, queria lhe roubar ainda a galinha e mesmo que a barriga da vizinha já se via, com o mona lá dentro, adiantaram pelejar" ("Estória da galinha e do ovo"), ou o presidiário, ex-músico, ex-engraxate, vendedor, servo de vários senhores chamado João Vêncio - um dos diversos nomes de Juvêncio Plínio do Amaral (João Vêncio: os seus amores, 1979). Dessa forma, ainda que haja personagens positivos no "mundo luandino" - como Lucas Matesso (Vidas novas, 1975) ou a personagem-título de A vida verdadeira de Domingos Xavier (1974) -, é a galeria de seres que vivem nas brechas, verdadeiros "pingentes" da vida, que nos chama a atenção. Não se pode deixar à margem, contudo, outra gama de personagens que comparece às estórias de Luandino Vieira: sãos os que habitam o mundo do maravilhoso, como a menina/musa Urania (No antigamente, na vida), de "um soletrado nome só", ou a Kianda do Kinaxixe e sua lagoa, que seria aterrada por conta do progresso. 
Trabalhadores ou farristas, maravilhosos ou nacionalistas, crianças como os miúdos Xico e Beto, ou mais-velhos - Vavó Bebeca e Vavó Xixi -, o que nos interessa dar relevo é que o africano habitante do musseque e seu imaginário tornam-se protagonistas das estórias, focalizados com dignidade, ao contrário do que ocorria na literatura colonial portuguesa, ganhando dimensões que excedem o documento, sendo alçados à esfera em que "na literatura, os tipos passam a representar os problemas comuns de nossa humanidade." (CANDIDO, 2004, p. 179). Ou seja, do musseque para o mundo, as personagens de Luandino Vieira falam de Luanda, de Angola e de todos nós.

Processo semelhante se dá com a Luanda que se descortina ao leitor. Todo um mapa da cidade capital aparentemente lhe é franqueado, e ele é seduzido pela miragem de uma cidade documentada e documental na ficção. Ora, se o Sambizanga e seus becos, assim como o Makulussu ou o Braga, são topônimos encontráveis na carta geográfica e referencialmente têm a sua existência assegurada, há, todavia, interseções entre bairros que desorientam o leitor e retiram-lhe as certezas: onde se localizaria mesmo "a confusão entre o Sambizanga e o Lixeira"? E os limites do Rangel? ("A estória do ladrão e do papagaio", Luuanda). Dessa forma, os musseques se sobrepõem e criam-se fronteiras improváveis, violentando a geografia.

E mais: se os limites entre os bairros e espaços não são localizáveis, as várias datas embaralham os mapas, e, assim, localidades que hoje são centrais, como a Maianga ou o Makulussu (Alto das Cruzes), apresentam-se nas narrativas nos arredores de Luanda. Para não nos referirmos a estórias como "Lá em Tetembuatubia", em que a geografia cede à imaginação infantil, ou ao texto em que uma "grande floresta" existe apenas para as crianças, sendo para os adultos um matagal ("Encontro de acaso", em $A$ cidade e a infância), ou ainda a "Memória narrativa ao sol do Kinaxixi”, em que uma lagoa e sua frondosa mafumeira (No antigamente, na vida) não serão encontradas na geografia atual da cidade, pois cederam vez ao asfalto ${ }^{6}$.

Não desanimemos o leitor, contudo. Munido de um mapa, ele poderá localizar em um passeio pela Luanda de hoje a "chorada Ingombota dos poetas populares e outros popularizados à toa" "“Muadiê Gil, o Sobral e o barril”, Velhas estórias), ainda que descaracterizada pelos edifícios modernos; o Sambizanga - "o mais cantado dos musseques" -, infelizmente tão pouco urbanizado quanto nas estórias luandinas dos anos 1960; ou então edifícios, como um colégio de arquitetura do Estado Novo, referido nos textos como "Colégio das Madres" (em Luuanda, por exemplo), o Colégio São José de Cluny, a Igreja de Nossa Senhora do Cabo, o velho edifício dos Correios e Telégrafos ou, ainda, a Igreja da Sé.

Reconfortado, o leitor prossegue sua leitura/busca convencido de que achou um fio condutor que lhe possibilitará construir um colar de contas geograficamente amigadas. Mas, felizmente, é ludibriado de novo: onde seria mesmo a "Quinta dos amores", bairro residencial da cidade à antiga, 
do conto "O nascer do sol" (A cidade e a infância)? Ou o musseque Makutu, "que nasceu às avessas", de "Estória da Menina Santa" (Velhas estórias)? A interrogação fica no ar, mas a tradução da palavra makutu, do quimbundo, fornece uma pista, na medida em que a palavra significa "mentira". O leitor finalmente entende que as necessidades de composição regem o relato e que os mapas devem ser deixados à parte, dando-se vez e voz às estórias.

Do ângulo que nos interessa, vale salientar que a geografia de Luandino é construída de virtualidades e atende sobretudo a uma necessidade de composição artística. Assim, os vários musseques referidos (e aqui um levantamento que realizamos nos textos do autor nos permite dizer que Kinaxixe, Sambizanga e Makulussu são os mais citados), bairros, ruas e logradouros - que vão do Museu de Angola ao Cemitério do Alto das Cruzes, passando pela calçada da loja Casa Comercial Catonho-Tonho e do Largo do Baleizão, por exemplo - são erigidos a partir um subterfúgio e da malícia. Explicitemos: o subterfúgio consiste em franquear ao leitor os espaços de exclusão brutal do colonizado de modo que logradouros a ele negados são percorridos nas estórias ao mesmo tempo em que os musseques são focalizados. Colocam-se em contraste, portanto, as duas cidades de que nos fala Fanon:

A zona habitada pelos colonizados não é complementar da zona habitada pelos colonos. Estas duas zonas se opõem mas não em função de uma unidade superior. Regidas por uma lógica puramente aristotélica, obedecem ao princípio da exclusão recíproca: não há conciliação possível, um dos termos é demais. (FANON, 1979, p. 28)

Destarte, o leitor, ao confrontar a Baixa e os musseques, vê-se transportado à vida da violenta segregação colonial. Por outro lado, há uma malícia nessa abertura de espaços, pois estabelece-se uma cumplicidade entre leitor e texto, de sorte que aquele passa a esposar a mesma perspectiva das personagens, vivenciando seus espaços, irmanando-se a elas.

E aqui nos referimos a uma terceira faceta do texto luandino que viemos explorando à luz das funções da literatura referidas por Antonio Candido. Trata-se de entender a literatura também como "uma forma de conhecimento, inclusive como incorporação difusa e inconsciente" de valores humanos, universais. Ou seja, a literatura como conhecimento que resulta em aprendizado. Mas um aprendizado distante da pedagogia ou das normas oficiais, conforme nos lembra Candido - daí as atitudes ambivalentes que suscita nos leitores, pois ensina, muitas vezes, em aspectos que a ideologia oficial dos estados gostaria de banir.

Segundo o crítico brasileiro, a literatura não corrompe nem edifica, mas, trazendo livremente em si o que chamamos bem e o que chamamos mal, humaniza em sentido profundo, porque faz viver. Assim, ao aprendizado algo dúbio sobre a geografia de Luanda e a língua ali falada, as narrativas de Luandino Vieira sobrepõem a experiência sobre a violência 
colonial e vivência dos espoliados. E esse aspecto é tão forte, que, como já referimos, quando o livro Luuanda foi premiado com o Grande Prêmio de Novelística no período colonial, em 1965, a PIDE assaltou e encerrou a Sociedade Portuguesa de Escritores (SPE), outorgante do prêmio, prendendo a maior parte do júri.

Ao lado desse elemento político de contestação, outras formas de bem e mal presentificam-se - sem preceitos morais - nas estórias luandinas. São práticas que a estreita social colonial determinava serem vícios, como a diamba fumada constantemente pela personagem Via Rápida, de "A estória da galinha e do ovo", em Luuanda -, ou o amor homossexual do menino João Vêncio em João Vêncio: os seus amores. Trata-se de características das personagens que auxiliam a constituir-lhes as contradições e, portanto, também a sua humanidade, na medida em que se aproximam de todos nós.

Dessa maneira, assim como a cidade de Luanda, ao receber um sofisticado tratamento artístico, acaba por ter a sua geografia embaralhada nas narrativas e torna-se espaço ficcional, conseguindo realizar o delicado e difícil equilíbrio entre História e estórias, também outras fronteiras no que concerne às crenças, personagens e costumes se diluem, contribuindo para fazer ceder o regional frente ao cosmopolitismo. Destarte, as histórias luandinas ultrapassam o musseque e a cidade de Luanda e deitam raízes no terreno da literatura, estabelecendo o que Antonio Candido chamaria de "universalidade da região" (CANDIDO, 1989, p. 162), em que o pitoresco e o documentário são ultrapassados, ainda que, dialeticamente, esse fato não torne menos viva a presença das cores locais.

Felizmente, nos textos de José Luandino Vieira, a geografia cede à ficção.

\section{REFERÊNCIAS BIBLIOGRÁFICAS}

CANDIDO, Antonio. A educação pela noite \& outros ensaios. São Paulo: Ática, 1989.

Vários escritos. Rio de Janeiro: Ouro sobre o azul, 2002.

FANON, Franz. Os condenados da terra. 2 ed. Trad. J. L. de Melo. Rio de Janeiro: Civilização brasileira, 1979.

PESAVENTO, Sandra Jatahy. Cidade visíveis, cidades sensíveis, cidades imaginárias. In: Revista Brasileira de História. vol. 27, n. 53. São Paulo: ANPHU, jun. 2007. p. 11-23.

PINTO, Alberto Oliveira. Quinaxixe de Arnaldo Santos: a formação do nacionalismo angolano na memória colonial de Luanda. In: LEITE, A. M., OWEN, H., CHAVES, R., APA, L. (Orgs.). Nação e Narrativa Pós-Colonial I. Angola e Moçambique. Ensaios, Lisboa: Edições Colibri, 2012. p. 19-35. 
RIBEIRO, Margarida Calafate. E Agora José, Luandino Vieira? Entrevista a José Luandino Vieira por ocasião dos 40 anos da publicação de Luuanda. In: Portuguese Literary \& Cultural Studies, Special issue "Remembering Angola”, out. 2006.

VIEIRA, José Luandino. A cidade e a infância. São Paulo: Companhia das letras, 2007.

- A vida verdadeira de Domingos Xavier. Lisboa: Caminho, 2003.

. João Vêncio: os seus amores. Lisboa: Caminho, 2004.

. Luuanda. São Paulo: Ática, 1982.

. No antigamente, na vida. Lisboa: Caminho, 2005.

. Velhas estórias. Lisboa: Caminho, 2006.

. Vida novas. Lisboa: Caminho, 2007.

TOPA, Francisco. Águas profundas são as palavras dos poetas: Luuanda e Luandino. In: As artes entre as letras. Porto: Universidade do Porto, 2014, p. 5-7.

TAVARES, Ana Paula. A cabeça de Salomé. Lisboa: Caminho, 2004.

Recebido para publicação em 01/11/2015

Aprovado em 08/02/2016

\section{NOTAS}

* Tania Macêdo é Professora Titular de Literaturas Africanas da Faculdade de Filosofia, Letras e Ciências Humanas da Universidade de São Paulo

2 Conforme se pode ler no magnífico Papéis da prisão (2015), em que - entre outras anotações e reflexões - se pode acompanhar a gênese dos contos que compõem o livro.

3 Referimo-nos a Luuanda 50 anos - Críticas, prêmios, protestos e silenciamento (TOPA, 2014, 324 p).

4 Tendo em vista que a maior parte dos textos de Luandino Vieira foram escritos na prisão, em razão de suas atividades anticoloniais, informamos no corpo do texto a data da edição que utilizamos, indicando abaixo o ano de redação dos mesmos: A vida verdadeira de Domingos Xavier - 1961; Luuanda - 1963; Vidas novas - 1962; Velhas estórias - 1964; No antigamente, na vida - 1969; Nós, os do Makulusu - 1967; Macandumba - 1971; João Vêncio: os seus amores - 1968.

5 “Cidades são pedra, aço, ferro, vidro, barro, equipamento, traçado. Mas cidades de pedra podem ser lidas, já dizia Walter Benjamin, e os procedimentos dessa leitura, que fazem da arquitetura uma narrativa, são quase os mesmos daqueles do discurso literário, complementava Paul Ricoeur" (PESAVENTO, 2007).

6 A respeito do Kinaxixe (ou Quinaxixe) e suas transformações, leia-se o texto de Alberto de Oliveira Pinto intitulado Quinaxixe de Arnaldo Santos: olhar identitário angolano sobre a memória colonial de Luanda. (PINTO, 2012, p. 22) 